\title{
Th-2 signature in chronic airway diseases: towards the extinction of asthma-COPD overlap syndrome?
}

\author{
Borja G. Cosío ${ }^{1,14}$, Luis Pérez de Llano ${ }^{2,14}$, Antolin Lopez Viña $\mathbb{1}^{3}$, \\ Alfons Torrego ${ }^{4}$, Jose Luis Lopez-Campos ${ }^{5}$, Joan B. Soriano $\mathbb{1}^{6}$, \\ Eva Martinez Moragon ${ }^{7}$, Jose Luis Izquierdo ${ }^{8}$, Irina Bobolea ${ }^{9}$, Javier Callejas ${ }^{10}$, \\ Vicente Plaza $\mathbb{1}^{4}$, Marc Miravitlles ${ }^{11}$ and Juan Jose Soler-Catalunya ${ }^{12,13}$ \\ on behalf of the CHACOS study group
}

Affiliations: ${ }^{1}$ Dept of Respiratory Medicine, Hospital Universitario Son Espases-IdISBa and Ciberes, Palma de Mallorca, Spain. ${ }^{2}$ Dept of Respiratory Medicine, Hospital Lucus Augusti, Lugo, Spain. ${ }^{3}$ Dept of Respiratory Medicine, Hospital Puerta de Hierro, Madrid, Spain. ${ }^{4}$ Dept of Respiratory Medicine, Hospital de la Santa Creu y Sant Pau, Barcelona, Spain. ${ }^{5}$ Dept of Respiratory Medicine, Hospital Virgen del Rocío, Sevilla, Spain. ${ }^{6}$ Catedra Linde-Universidad Autónoma de Madrid, Hospital de la Princesa, Madrid, Spain. ${ }^{7}$ Dept of Respiratory Medicine, Hospital Dr Peset, Valencia, Spain. ${ }^{8}$ Dept of Respiratory Medicine, Hospital Universitario de Guadalajara, Guadalajara, Spain. ${ }^{9}$ Dept of Allergy, Hospital 12 de Octubre, Madrid, Spain. ${ }^{10}$ Dept of Respiratory Medicine, Hospital Universitario de Albacete, Albacete, Spain. ${ }^{11}$ Dept of Respiratory Medicine, Hospital Universitari Vall d'Hebron, Barcelona, Spain. ${ }^{12}$ Dept of Respiratory Medicine, Hospital Arnau de Vilanova, Valencia, Spain. ${ }^{13}$ The names and affiliations of the CHACOS study group are listed in the supplementary material. ${ }^{14} \mathrm{Co}$-primary authors.

Correspondence: Borja G. Cosío, Dept of Respiratory Medicine, Hospital Universitario Son Espases, Ctra. de Valldemossa 79, 07010 Palma de Mallorca, Spain. E-mail: borja.cosiodssib.es

@ERSpublications

Identifying a Th-2 signature in patients with chronic airflow limitation effectively differentiates treatable traits http://ow.ly/kq1E309MMkt

Cite this article as: Cosío BG, Pérez de Llano L, Lopez Viña A, et al. Th-2 signature in chronic airway diseases: towards the extinction of asthma-COPD overlap syndrome?. Eur Respir J 2017; 49: 1602397 [https://doi.org/10.1183/13993003.02397-2016]

ABSTRACT We aimed to describe the differences and similarities between patients with chronic obstructive airway disease classified on the basis of classical diagnostic labels (asthma, chronic obstructive pulmonary disease (COPD), or asthma-COPD overlap (ACOS)) or according to the underlying inflammatory pattern (Th-2 signature, either Th-2-high or Th-2-low).

We performed a cross-sectional study of patients aged $\geqslant 40$ years and with a post-bronchodilator forced expiratory volume in $1 \mathrm{~s}$ to forced vital capacity ratio $\leqslant 0.7$ with a previous diagnosis of asthma (nonsmoking asthmatics (NSA)), COPD or ACOS, the latter including both smoking asthmatics (SA) and patients with eosinophilic COPD (COPD-e). Clinical, functional and inflammatory parameters (blood eosinophil count, IgE and exhaled nitric oxide fraction $\left(F_{\mathrm{eNO}}\right)$ ) were compared between groups. Th-2 signature was defined by a blood eosinophil count $\geqslant 300$ cells $\mu \mathrm{L}^{-1}$ and/or a sputum eosinophil count $\geqslant 3 \%$.

Overall, 292 patients were included in the study: 89 with COPD, 94 NSA and 109 with ACOS (44 SA and 65 with COPD-e). No differences in symptoms or exacerbation rate were found between the three groups. With regards the underlying inflammatory pattern, 94 patients $(32.2 \%)$ were characterised as Th2-high and 198 (67.8\%) as Th-2-low. The Th-2 signature was found in 49\% of NSA, 3.3\% of patients with COPD, $30 \%$ of SA and $49.3 \%$ of patients with COPD-e. This classification yielded significant differences in demographic, functional and inflammatory characteristics.

We conclude that a classification based upon the inflammatory profile, irrespective of the taxonomy, provides a more clear distinction of patients with chronic obstructive airway disease. 


\section{Introduction}

Asthma and chronic obstructive pulmonary disease (COPD) are two common diseases in the general population that occasionally may share similar clinical features and physiopathological mechanisms $[1,2]$. Irrespective of whether or not asthma and COPD share a common origin, they are both heterogeneous conditions that can present with a wide range of clinically overlapping pictures, commonly labelled as phenotypes. However, this approach does not take into account the growing knowledge about molecular pathways (i.e. endotypes) that has allowed novel therapeutic strategies to be developed that target specific components of the underlying inflammatory process. As a consequence, some experts have proposed to move to a precision medicine scenario that takes into consideration causal mechanistic disease pathways in order to plan treatment according to "treatable traits", specific for each patient [3]. So far, only markers of Th-2 inflammation (e.g. sputum or blood eosinophil counts, exhaled nitric oxide, periostin, IgE) have been incorporated into the diagnostic and therapeutic process for patients with chronic obstructive airway disease (COAD). Current evidence suggests that eosinophilia is associated with COPD treatment response and natural history $[4,5]$. Moreover, a Th-2 signature in smokers and ex-smokers with COPD is associated with an increased blood eosinophil count, bronchial hyper-responsiveness and a response to inhaled corticosteroids (ICS) that is not predicted by a previous history of asthma [6]. The classification of asthmatic patients based on their inflammatory pattern (namely "Th-2-high" and "Th-2-low") has allowed the development of new biological agents [7].

The so-called asthma-COPD overlap syndrome (ACOS) has recently gained attention but, to date, there is no universally accepted definition of this entity though some efforts have been undertaken to characterise it [8-11]. One of the reasons for this confusion might be that all the clinical studies carried out to describe ACOS have included selected cohorts of patients with asthma or COPD instead of considering COAD as a whole. Such an approach is clearly inadequate to address some important clinical questions, such as, to what extent are COPD with eosinophilia and asthma with chronic airflow limitation in smokers the same entity.

The objective of this study was to describe the demographic, clinical and physiological differences and similarities between patients with COAD classified either on the basis of classical diagnostic labels (asthma in non-smoking asthmatics (NSA), COPD or ACOS, the latter including smoking asthmatics (SA) and patients with eosinophilic COPD (COPD-e)) or according to the underlying inflammatory pattern (Th-2 high and Th-2 low). As a secondary objective, we aimed to explore how the new proposed criteria to define ACOS [9] fit into the different categories.

\section{Material and methods Study design}

We carried out a cross-sectional, observational, multicentre study in 23 outpatient clinics based in tertiary hospitals in Spain run by expert respiratory physicians. Investigators were asked to recruit consecutive patients with asthma, including smoking and non-smoking patients and patients with COPD with and without a blood eosinophil count $\geqslant 200$ eosinophils $\mu \mathrm{L}^{-1}$.

The study was approved by the Research Ethics Committee of the Balearic Islands (Cod: IB2499/15). Additionally, an independent ethics committee or institutional review board for each study centre approved the final protocol. The STROBE standards (STrengthening the Reporting of OBservational studies in Epidemiology) for reporting observational studies were followed.

\section{Patients}

We included male and female patients aged $\geqslant 40$ years with a history of physician-diagnosed asthma or COPD (as defined below) and chronic airflow obstruction (a post-bronchodilator forced expiratory volume in $1 \mathrm{~s}(\mathrm{FEV} 1)$ to forced vital capacity (FVC) ratio $\leqslant 0.70)$ who signed an informed, written consent form. Patients had to be in a stable condition, free from exacerbations for at least 3 months. Exclusion criteria included primary bronchiectasis, active cancer (metastatic, progressive or treated within the last

This article has supplementary material available from erj.ersjournals.com

Received: Dec 062016 | Accepted after revision: March 022017

Support statement: The project was endorsed by the COPD and Asthma Research Board of the Spanish Society of Respiratory Medicine (SEPAR). The project was partially funded by the Fondo de Investigaciones Sanitarias, Instituto de Salud Carlos III, Ministerio de Economia y Competitividad (FIS 15/01263) and by an unrestricted grant from Chiesi Pharmaceutici SpA. Chiesi had no role in the study design, data collection, data analysis, data interpretation, writing of the report, or in the decision to submit the article for publication. The corresponding author had full access to all the data in the study and had final responsibility for the decision to submit for publication. Funding information for this article has been deposited with the Crossref Funder Registry.

Conflict of interest: Disclosures can be found alongside this article at erj.ersjournals.com 
24 months), chronic inflammatory diseases and a poor performance status. Active smoking was not an exclusion criterion.

\section{Definitions}

-Non-smoking asthmatics (NSA): patients with a history of physician-diagnosed asthma according to international guidelines [8], with chronic airflow obstruction, who were either never-smokers or ex-smokers with a smoking history of $\leqslant 10$ pack-years.

-Smoking asthmatics (SA): asthma patients with chronic airflow obstruction and a smoking history of $\geqslant 20$ pack-years.

-COPD: diagnosed according to international recommendations [2] by the presence of a postbronchodilator $\mathrm{FEV}_{1} / \mathrm{FVC} \leqslant 0.70$ in patients with a smoking history of $\geqslant 10$ pack-years in the absence of clinical suspicion for asthma.

-COPD with eosinophilia (COPD-e): COPD patients with an eosinophil count $\geqslant 200$ eosinophils $\mu \mathrm{L}^{-1}$ in blood. We selected this threshold because below this cut-off patients are unlikely to have sputum eosinophilia, according to published evidence [12].

-ACOS: We considered this diagnosis if the patient, previously diagnosed with asthma, had chronic airflow limitation and a smoking history $\geqslant 20$ pack-years, or if a patient with a diagnosis of COPD had a blood eosinophil count $\geqslant 200$ eosinophils $\mu \mathrm{L}^{-1}$. We also tested in our population the validity of the latest expert consensus definition of ACOS [9], which is the presence of chronic airflow limitation (a post-bronchodilator $\mathrm{FEV} 1 / \mathrm{FVC} \leqslant 0.7$ ) in patients $\geqslant 40$ years with a smoking history of $\geqslant 10$ pack-years and a documented history of asthma or a large bronchodilator response (defined by an increase in FEV 1 $\geqslant 400 \mathrm{~mL}$ and $\geqslant 15 \%$ ) in whom one of the following characteristics is present: history of atopy or allergic rhinitis, blood eosinophil count $\geqslant 300$ cells $\mu \mathrm{L}^{-1}$ or a bronchodilator response (increase in FEV $1 \geqslant 200 \mathrm{~mL}$ and $12 \%$ ) in two or more visits.

-COAD with Th-2-high: Patients with a post-bronchodilator FEV1/FVC $\leqslant 0.70$ and an eosinophil count $\geqslant 300$ eosinophils $\mu \mathrm{L}^{-1}$ in blood or $\geqslant 3 \%$ in sputum.

-COAD with Th-2-low: Patients with a post-bronchodilator FEV1/FVC $\leqslant 0.70$ and an eosinophil count $\leqslant 300$ eosinophils $\mu \mathrm{L}^{-1}$ in blood and $\leqslant 3 \%$ in sputum.

-Exacerbation: Sustained worsening of the patient's condition, sufficient to warrant treatment with antibiotic or oral corticosteroid therapy or admission to hospital. Each episode must have been recorded in the medical chart.

\section{Measurements}

The study was conducted in a single visit in which the researchers obtained and recorded all the clinical data into an electronic clinical research database. A blood sample was obtained to determine the number and percentage of blood eosinophils and to quantify the level of IgE. Atopy was assessed by a skin prick test. The degree of compliance with inhalers was estimated using the Test of Adherence to Inhalers [13].

Pulmonary function tests and measurement of the exhaled nitric oxide fraction (FeNO) were performed following American Thoracic Society (ATS)/European Respiratory Society (ERS) guidelines [14-16].

Sputum induction was performed in 32 patients, in selected centres, according to the ERS recommendations [17]. We adopted a sputum eosinophil count of $3 \%$ as the threshold for defining eosinophilic or non-eosinophilic airway inflammation, as described elsewhere [18].

\section{Statistical analysis}

Data are summarised as relative frequencies for categorical variables, mean $\pm \mathrm{sD}$ for normally distributed scale variables, and frequency and percentage for ordinal or non-normal scale variables. To compare differences between groups, an ANOVA or Kruskal-Wallis test was used for parametric continuous or nonparametric continuous variables, respectively. To compare categorical variables, a Pearson's Chi-squared test or Fisher's exact test (when applicable) was used. The Bonferroni correction was used to control for type I errors. The significance level was established as a two-tailed p-value $<0.05$.

\section{Results}

Population characteristics

In total, 292 patients with COAD were included in the study (figure 1): 94 NSA, 89 with COPD and 109 with ACOS (44 SA and 65 with COPD-e). The demographic, clinical and functional characteristics of the entire sample are reported in table 1. Briefly, the degree of bronchial obstruction was moderate and symptoms were fairly controlled as assessed by the COPD Assessment Test (CAT) and Asthma Control Test (ACT) questionnaires. The average number of exacerbations in the course of the previous 12 months was $1.0 \pm 1.35$. Most patients $(80 \%)$ were treated with ICS and almost all of them received a long-acting 


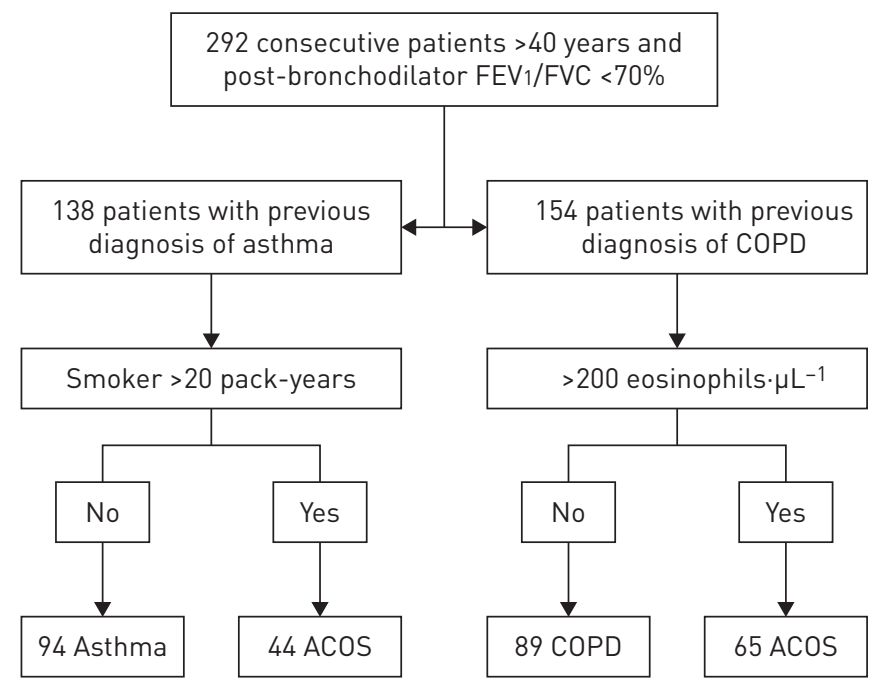

FIGURE 1 Flow-chart diagram of recruitment process. FEV1: forced expiratory volume in $1 \mathrm{~s}$; FVC: forced vital capacity; COPD: chronic obstructive pulmonary disease; ACOS: asthma-COPD overlap syndrome.

$\beta_{2}$-agonist (LABA). About $71 \%$ were being treated with a long-acting muscarinic antagonist (LAMA) (table 1). Corrected post hoc p-values for two-group comparisons are shown in supplemental table S1.

Characteristics of patients with chronic obstructive airway disease according to current taxonomy NSA patients were middle-aged $(61.1 \pm 12.3$ years), predominantly female, with frequent symptoms of rhinitis (53\%) and the most preserved pulmonary function (mean post-bronchodilator FEV1: $69.5 \pm 18.9 \%$ of reference value). They showed the highest values for blood eosinophil count, FeNO, and IgE (table 1). Virtually all of these patients were receiving a combination of ICS with LABA and $>50 \%$ were also treated with LAMA as an add-on therapy. About $17 \%$ were on omalizumab, whereas only $6.4 \%$ were receiving oral corticosteroids (table 1). Within the previous year, $47 \%$ had at least one exacerbation. The mean number of exacerbations in the previous year was $0.97 \pm 1.37$. In this group, none of the patients met the consensus criteria for ACOS.

COPD patients were older (67.9 \pm 8.6 years), predominantly male, and had the most severe airflow limitation (mean post-bronchodilator FEV1: 55.1 $\pm 18.5 \%$; diffusing capacity of the lung for carbon monoxide (DLCO): 63.6 \pm 25.9$)$ and the highest smoking history. This group also had the lowest values for blood eosinophil count, FeNO and IgE among the three groups (table 1). The majority of these patients were being treated with a combination of LABA and LAMA but $66 \%$ of them were also receiving ICS (table 1 ). Within the previous year, $52 \%$ had at least one exacerbation. The mean number of exacerbations in the previous year was $1.08 \pm 1.32$. In this group, $5.6 \%$ of the patients met the consensus criteria for ACOS. None of them had a previous history of asthma but all had a high response to bronchodilation plus a history of atopy.

\section{Characteristics of patients with chronic obstructive airway disease included in the category of asthma-COPD overlap syndrome}

The ACOS category included 109 patients (44 SA and 65 COPD-e). When compared with the NSA and COPD patients, we found no differences in symptoms or exacerbations. ACOS patients showed similar demographic and inflammatory characteristics to those with asthma and functional impairment and a comorbidity profile similar to those in the COPD group (table 1). About $75 \%$ of these patients were taking ICS regularly, almost all of them (93\%) were receiving a LABA, 73\% were treated with a LAMA and $8.6 \%$ were on omalizumab treatment (table 1). In this category, $38.5 \%$ of the patients met the consensus criteria for ACOS [9]. The patients who met the consensus criteria for ACOS were younger and had a lower smoking history, a more frequent history of rhinitis and better lung function than those considered to have ACOS according to our definitions (supplemental table S2).

There were important differences between patients included in the category of ACOS depending on whether the patient had a diagnosis of SA or of COPD-e (table 2 and figure 2). Patients classified with COPD-e showed significantly lower post-bronchodilator FEV1 than SA patients $(54.49 \pm 15.2$ versus 65.57 $\pm 17.5 \%$; $\mathrm{p}=0.005)$, but a higher blood eosinophil count $\left(374.9 \pm 156\right.$ versus $262.1 \pm 189$ cells $\left.\cdot \mu \mathrm{L}^{-1}, \mathrm{p}<0.002\right)$ and a non-statistically significant trend for higher $F$ eNO values $(24.6 \pm 25.4$ versus $19.6 \pm 11 \mathrm{ppb}, \mathrm{p}=0.237)$ than those found in the SA group. 
TABLE 1 Characteristics of patients according to the baseline diagnosis

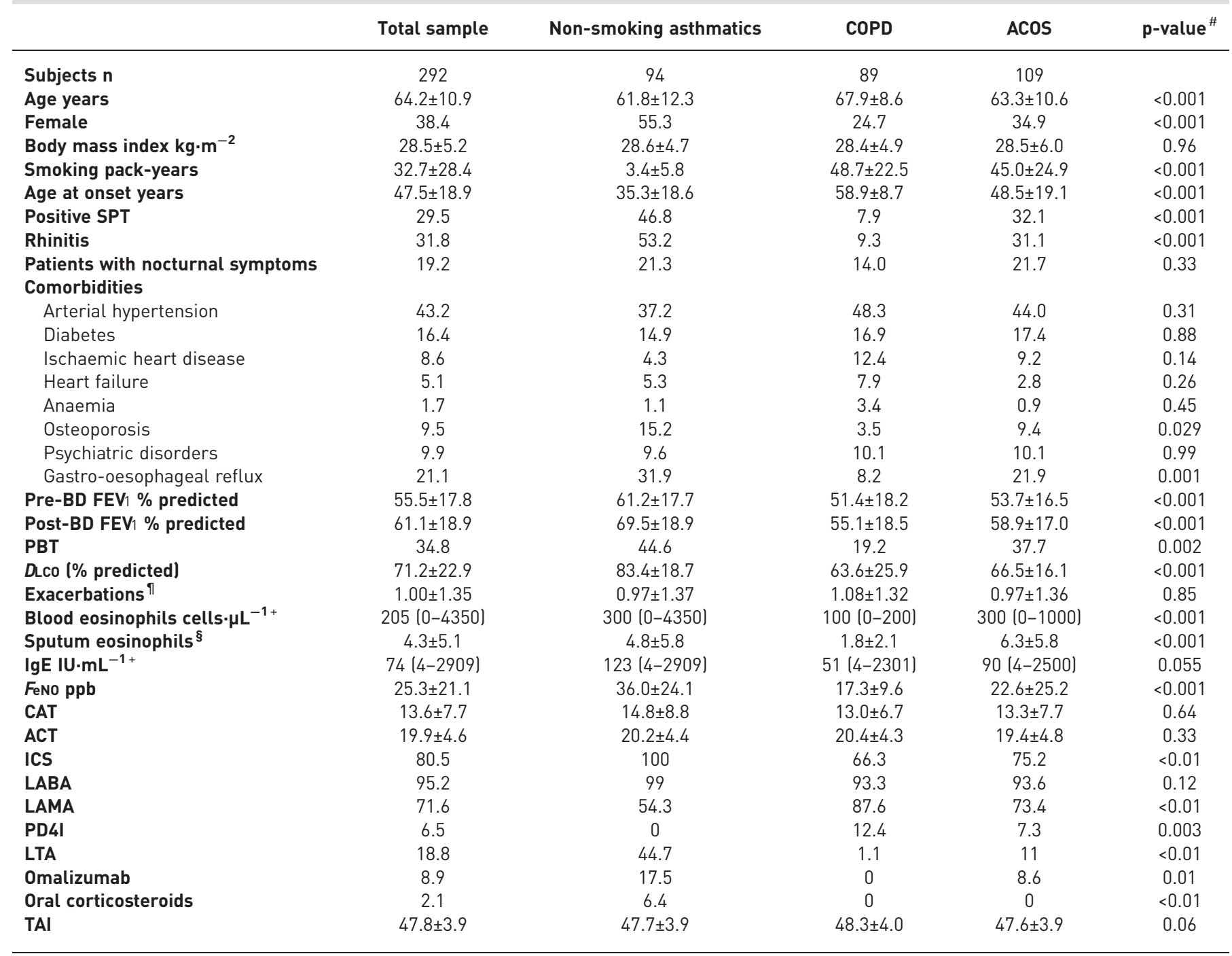

Data are presented as mean \pm SD or percentages, unless otherwise stated. COPD: chronic obstructive pulmonary disease; ACOS: asthma-COPD overlap syndrome; SPT: skin prick test; pre-BD: pre-bronchodilator; FEV1: forced expiratory volume in 1 s; post-BD: post-bronchodilator; PBT: positive bronchodilator test; DLCO: carbon monoxide diffusing capacity; FeNo: exhaled nitric oxide fraction; CAT: COPD Assessment Test; ACT: Asthma Control Test; ICS: inhaled corticosteroids; LABA: long-acting $\beta 2$-agonists; LAMA: long-acting muscarinic antagonists; PD4I: phosphodiesterase 4 inhibitors; LTA: leukotriene receptor antagonists; TAl: Test of Adherence to Inhalers score. ${ }^{\#}$ : $p$-value represents

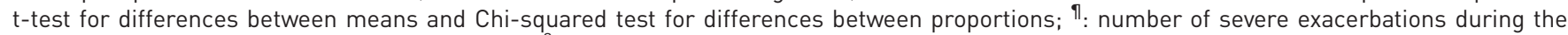
past 12 months; ${ }^{+}$: presented as median (range); ${ }^{\S}: \mathrm{n}=35$.

The SA group showed similar demographic and functional characteristics to those in the NSA group, with frequent symptoms of rhinitis (51\%) and positive results in skin prick tests (45.5\%). However, blood eosinophil count and FeNO values were lower than those found in the NSA group (262.1 \pm 189 versus 395.5 \pm 505 cells $\mu \mathrm{L}^{-1}, \mathrm{p}<0.001$ and $19.6 \pm 17$ versus $36.0 \pm 27 \mathrm{ppb}, \mathrm{p}<0.001$, respectively). The therapeutic approach was similar in NSA and SA. In the previous year, $52 \%$ of patients had at least one exacerbation. The mean number of exacerbations in the previous year was $1.00 \pm 1.36$. In this subgroup, $77.3 \%$ of the patients met the consensus criteria for ACOS. Those patients who did not meet the criteria had a previous diagnosis of asthma but did not meet any of the minor criteria to be considered under ACOS: no atopy, no rhinitis, no bronchodilator response and no eosinophil count $\geqslant 300$ cells $\mu \mathrm{L}^{-1}$.

Patients with COPD-e showed similar smoking habits and demographic and functional characteristics to those in the COPD category with the exception of more reversibility of the airflow obstruction (positive bronchodilator test $30.2 \%$ versus $19.2 \%$ ). However, although the blood eosinophil counts were higher than those found in the COPD group $\left(374.9 \pm 156\right.$ versus $118.2 \pm 63$ cells $\left.\mu \mathrm{L}^{-1}, \mathrm{p}<0.001\right)$, differences in FeNO 
TABLE 2 Differential characteristics within the asthma-COPD overlap syndrome group: smoking asthmatics versus eosinophilic COPD

\begin{tabular}{|c|c|c|c|}
\hline & Smoking asthmatic & Eosinophilic COPD & p-value \\
\hline Age years & $59.86 \pm 10.5$ & $65.65 \pm 10.1$ & 0.007 \\
\hline Female & 59 & 18 & $<0.001$ \\
\hline Smoking packs-years & $35.0 \pm 13.2$ & $51.8 \pm 28.5$ & $<0.001$ \\
\hline Positive SPT & 45.5 & 23.1 & 0.003 \\
\hline Rhinitis & 51.2 & 17.5 & 0.001 \\
\hline Post-BD FEV $1 \%$ predicted & $65.57 \pm 17.5$ & $54.49 \pm 15.2$ & 0.005 \\
\hline Blood eosinophil count cells $\mu \mathrm{L}^{-1}$ & $262.07 \pm 189$ & $374.97 \pm 156.9$ & 0.002 \\
\hline FenO ppb & $19.5 \pm 14.0$ & $24.5 \pm 25.4$ & $<0.001$ \\
\hline Exacerbations $\#$ & $1.00 \pm 1.36$ & $0.95 \pm 1.37$ & 0.62 \\
\hline CAT & $13.2 \pm 8.0$ & $13.4 \pm 7.7$ & 0.83 \\
\hline ACT & $19.5 \pm 4.9$ & $19.2 \pm 4.8$ & 0.54 \\
\hline \multicolumn{4}{|c|}{$\begin{array}{l}\text { Data are presented as mean } \pm \text { SD or percentages. COPD: chronic obstructive pulmonary disease; SPT: skin } \\
\text { prick test; post-BD: post-bronchodilator; FEV1: forced expiratory volume in } 1 \mathrm{~s} \text {; FeNO: exhaled nitric oxide } \\
\text { fraction; CAT: COPD Assessment Test; ACT: Asthma Control Test. " }{ }^{\text {: }} \text { number of severe exacerbations during } \\
\text { the past } 12 \text { months. }\end{array}$} \\
\hline
\end{tabular}

values did not reach statistical significance $(24.6 \pm 25.4$ versus $17.3 \pm 9.6 \mathrm{ppb}, \mathrm{p}>0.05)$. The therapeutic regimen was similar to that in the COPD group. In the previous year, $49 \%$ of patients had at least one exacerbation. The mean number of exacerbations in the previous year was $0.95 \pm 1.37$. In this subgroup, $12.3 \%$ met the consensus criteria for ACOS. None of them had a previous history of asthma but had a high bronchodilator response plus atopy, rhinitis or a blood eosinophil count $\geqslant 300$ cells $\mu \mathrm{L}^{-1}$.
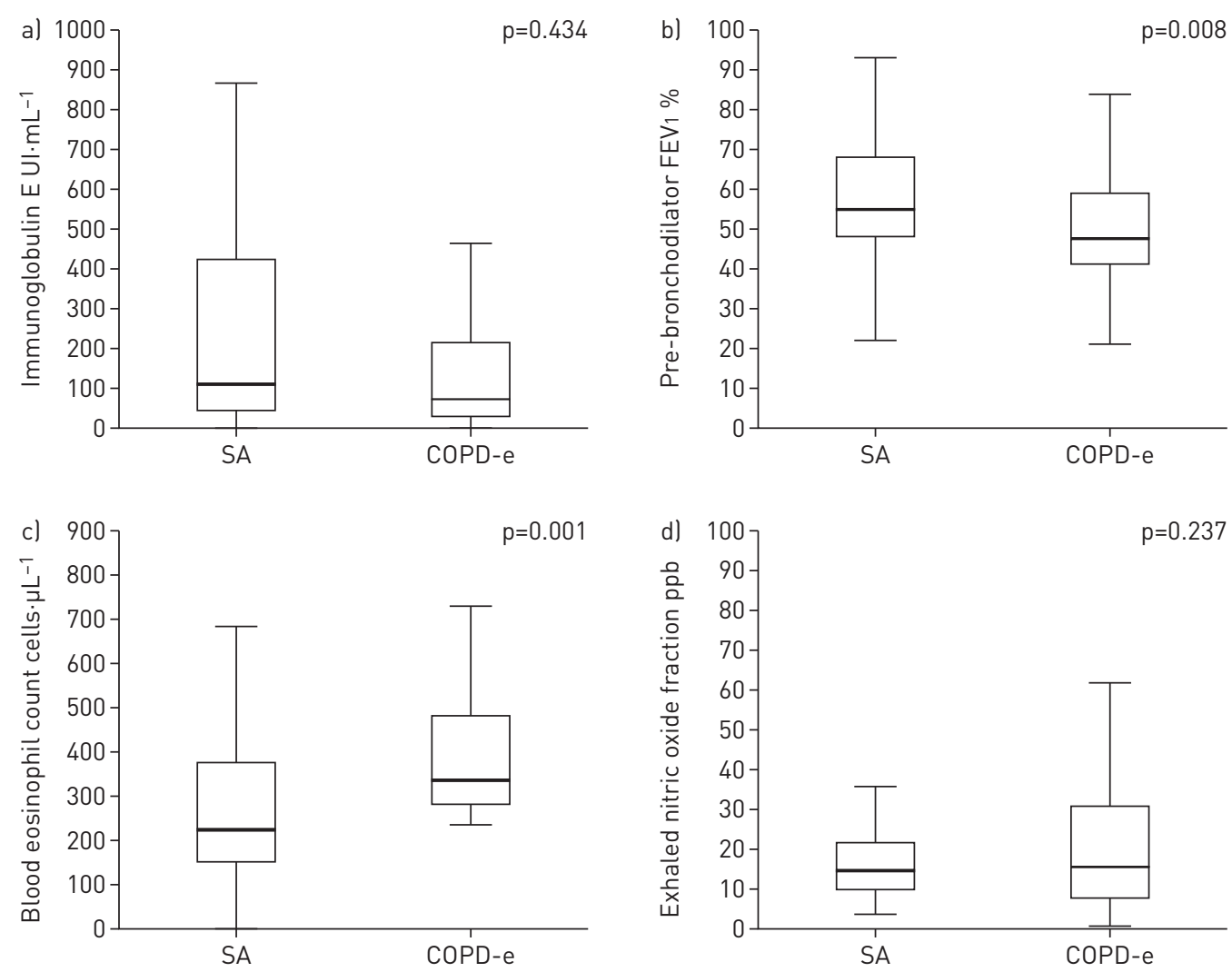

FIGURE 2 Differential characteristics within the asthma-chronic obstructive pulmonary disease overlap syndrome group: smoking asthmatics (SA) versus eosinophilic COPD (COPD-e). FEV1: forced expiratory volume in $1 \mathrm{~s}$. 


\section{Characteristics of patients with chronic obstructive airway disease according to the underlying} inflammatory profile

Out of the 292 patients included in the study, 94 (32.2\%) were characterised as Th-2-high and 198 as Th-2-low. Th-2 signature was found in $49 \%$ of NSA, 3.3\% of patients with COPD, 30\% of SA and $49.3 \%$ of patients with COPD-e (figure 3). The criteria for ACOS was met by $22 \%$ of patients categorised as Th-2-high and $18.7 \%$ of patients categorised as Th-2-low.

Th-2-high patients were significantly younger $(60.9 \pm 12.3$ versus $65.8 \pm 9.8$ years; $\mathrm{p}=0.003)$ with a longer history of symptoms (age of onset: $41.0 \pm 19.1$ versus $50.5 \pm 18.0$ years; $\mathrm{p}<0.001$ ). No gender differences were seen between groups. Th-2-high patients had a more frequently positive skin prick test $(46.8 \%$ versus $21.2 \%$; $\mathrm{p}<0.01)$ as well as more frequent rhinitis $(55.5 \%$ versus $22.8 \%$; $<<0.001)$ and polyposis $(24.7 \%$ versus $4.9 \%$; $\mathrm{p}<0.001$ ). Pulmonary function was significantly better in Th-2-high patients (post-bronchodilator FEV1: $1779 \pm 751$ versus $1593 \pm 697 \mathrm{~mL}, \mathrm{p}=0.01)$. There were no differences in the total number of exacerbations $(2.2$ \pm 1.5 versus $1.8 \pm 1.1 ; \mathrm{p}=0.18)$ or in symptoms assessed by CAT $(14.3 \pm 8$ versus $13.3 \pm 7 ; \mathrm{p}=0.38)$ and ACT ( $19.4 \pm 4$ versus $20.2 \pm 4 ; \mathrm{p}=0.28)$ questionnaires. Th-2-high patients had more corticosteroid-treated exacerbations $(0.97 \pm 1.46$ versus $0.57 \pm 0.97 ; \mathrm{p}=0.057)$. Th- 2 biomarkers were significantly higher in Th- 2 -high patients, including blood eosinophil count (median 450 versus 180 cells $\mu \mathrm{L}^{-1} ; \mathrm{p}<0.01$ ), IgE (median 143 versus $64 \mathrm{UI} \cdot \mathrm{mL}^{-1} ; \mathrm{p}<0.001$ ) and FeNO (median 28 versus $15 \mathrm{ppb} ; \mathrm{p}<0.001$ ) (table 3 and figure 4).

No differences were found between the two groups in the percentages of patients who were taking ICS, LABA, LAMA, oral corticosteroids and omalizumab (table 3).

\section{Discussion}

We have shown that the current distinction between asthma, COPD and their overlap (ACOS) may be confusing because it includes a variety of disease expressions that cannot be separated clinically, and that a view of COAD based on the presence of a Th-2 signature is feasible and more effective for identifying treatable traits.

Patients with COPD and NSA patients with chronic airway obstruction share common symptoms, but they can be distinguished based on demographic, atopic and functional features. However, ACOS manifestations are somewhere between COPD and asthma, given that these patients showed analogous

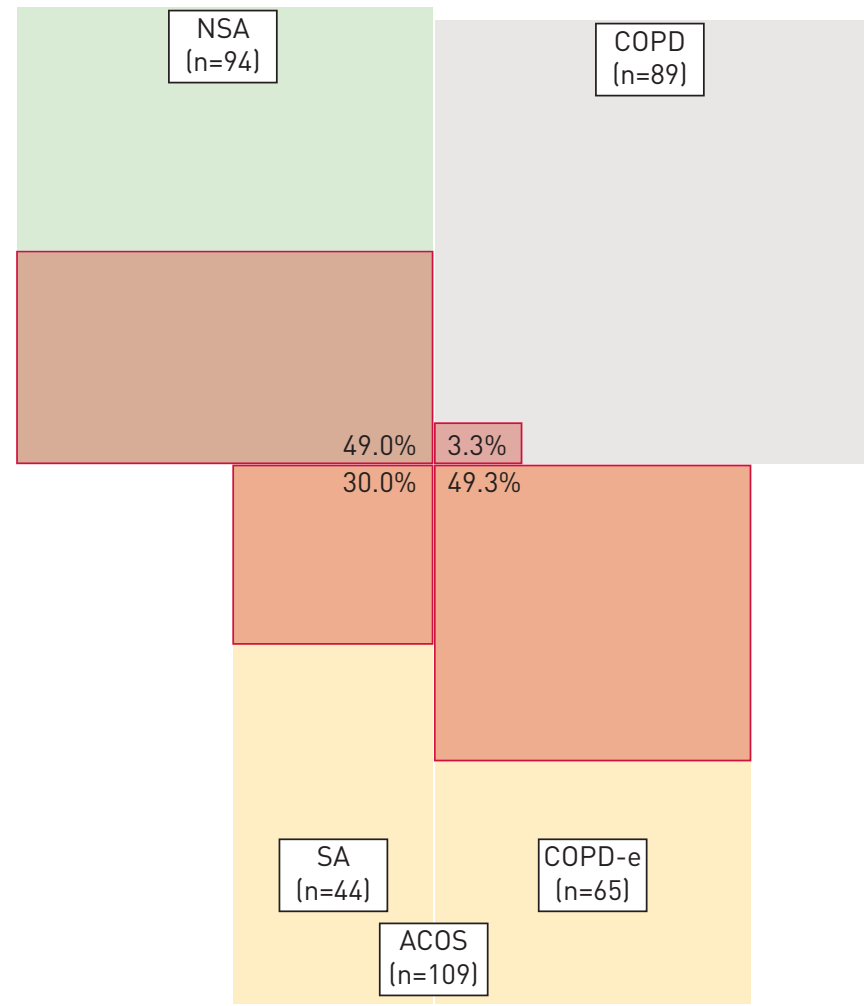

FIGURE 3 Proportional squares showing the percentage Th-2 signature in patients with chronic obstructive pulmonary disease (COPD), asthma, or asthma-COPD overlap syndrome (ACOS), the latter comprising smoking asthmatics (SA) and patients with eosinophilic COPD (COPD-e). 
TABLE 3 Differential characteristics according to the baseline inflammatory pattern

\begin{tabular}{|c|c|c|c|}
\hline & Th-2-high & Th-2-low & $\mathrm{p}$-value \\
\hline Subjects n & 94 & 198 & \\
\hline Age years & $60.5 \pm 12.3$ & $65.8 \pm 9.8$ & 0.003 \\
\hline Female & 41.5 & 36.9 & 0.52 \\
\hline Body mass index $\mathrm{kg} \cdot \mathrm{m}^{-2}$ & $28.6 \pm 5.7$ & $28.5 \pm 5.0$ & 0.52 \\
\hline Smoking pack-years & $34.9 \pm 27.7$ & $43.5 \pm 24.8$ & 0.01 \\
\hline Age of onset years & $41.0 \pm 19.1$ & $50.5 \pm 18.0$ & $<0.001$ \\
\hline SPT & 46.8 & 21.2 & $<0.01$ \\
\hline Rhinitis & 50.5 & 22.8 & $<0.001$ \\
\hline Polyposis & 24.7 & 4.9 & $<0.001$ \\
\hline Patients with nocturnal symptoms & 17.2 & 20.2 & 0.65 \\
\hline \multicolumn{4}{|l|}{ Comorbidities } \\
\hline Arterial hypertension & 34.04 & 47.47 & 0.03 \\
\hline Diabetes & 13.8 & 17.6 & 0.40 \\
\hline Ischaemic heart disease & 3.19 & 11.1 & 0.024 \\
\hline Heart failure & 2.13 & 6.5 & 0.18 \\
\hline Anaemia & 2.1 & 1.5 & 0.70 \\
\hline Osteoporosis & 11.9 & 8.3 & 0.33 \\
\hline Psychiatric disorders & 9.5 & 10.1 & 0.88 \\
\hline Gastro-oesophageal reflux & 20.7 & 21.4 & 0.99 \\
\hline Pre-BD FEV $1 \mathrm{~mL}$ & $1628 \pm 707$ & $1387 \pm 623$ & 0.007 \\
\hline Post-BD FEV1 mL & $1779 \pm 751$ & $1543 \pm 697$ & 0.018 \\
\hline PBT & 36.3 & 34.1 & 0.38 \\
\hline Exacerbations ${ }^{\#}$ & $1.15 \pm 1.5$ & $0.93 \pm 1.2$ & 0.57 \\
\hline OC exacerbations $"$ & $0.97 \pm 1.46$ & $0.57 \pm 0.97$ & 0.05 \\
\hline Blood eosinophils cells $\mu \mathrm{L}^{-1+}$ & $450(60-4350)$ & $180(0-280)$ & $<0.01$ \\
\hline Sputum eosinophils & $6.9 \pm 5.4$ & $0.9 \pm 1.1$ & $<0.01$ \\
\hline FenO ppb $^{+}$ & $28(4-157)$ & $15(1-76)$ & $<0.001$ \\
\hline $\lg E$ IU.mL $\mathrm{mL}^{-1+}$ & $143(4-2500)$ & 64 (4-2909) & $<0.001$ \\
\hline CAT & $14.3 \pm 8$ & $13.3 \pm 7$ & 0.38 \\
\hline ACT & $19.4 \pm 4$ & $20.2 \pm 4$ & 0.28 \\
\hline ICS & 84.0 & 78.8 & 0.29 \\
\hline LABA & 93.6 & 96.0 & 0.38 \\
\hline LAMA & 67.0 & 73.7 & 0.23 \\
\hline PD4I & 2.1 & 8.6 & 0.03 \\
\hline LTA & 31.9 & 12.6 & $<0.001$ \\
\hline Omalizumab & 10.7 & 8.1 & 0.52 \\
\hline OC & 2.1 & 2.0 & 0.95 \\
\hline TAI & $47.5 \pm 4.0$ & $48.0 \pm 3.9$ & 0.05 \\
\hline
\end{tabular}

Data are presented as mean \pm SD or percentages, unless otherwise stated. SPT: skin prick test; pre-BD: pre-bronchodilator; $\mathrm{FEV}_{1}$ : forced expiratory volume in $1 \mathrm{~s}$; post-BD: post-bronchodilator; PBT: positive bronchodilator test; OC: oral corticosteroids; FeNO: exhaled nitric oxide fraction; CAT: COPD Assessment Test; ACT: Asthma Control Test; ICS: inhaled corticosteroids; LABA: long-acting $\beta 2$-agonists; LAMA: long-acting muscarinic antagonists; PD4I: phosphodiesterase 4 inhibitors; LTA: leukotriene receptor antagonists; TAl: Test of Adherence to Inhalers score. " : number of severe exacerbations during the past 12 months; ${ }^{\text {ๆ: }}$ number of severe exacerbations treated with OC during the past 12 months; ${ }^{+}$: presented as median (range)

demographic and inflammatory characteristics to those with asthma, as well as functional impairment and comorbidities similar to those included in the COPD group. If we apply the criteria proposed by an expert panel [9] to identify ACOS patients, we could classify in this category $11.7 \%$ of the NSA patients, $5.6 \%$ of the COPD patients, $77.3 \%$ of the SA patients and $12.3 \%$ of the COPD-e patients. Therefore, these criteria mainly identify as ACOS asthmatic patients who have smoked and developed a "fixed bronchial obstruction", but also a non-negligible number of patients diagnosed with COPD or asthma by their physicians. If we consider ACOS as the coincidence of two different diseases (asthma and COPD) in the same individual, we should expect a mixed inflammatory pattern with some "Th-2-high" expression, and this situation might occur in both SA and COPD-e patients. However, we found significant differences between these two subgroups: SA patients had similar demographic and functional characteristics as NSA patients, but only $30 \%$ of them showed a Th-2-high inflammatory pattern (versus $49 \%$ in the NSA group). COPD-e patients had similar demographic and functional features as patients with "pure COPD", but the 

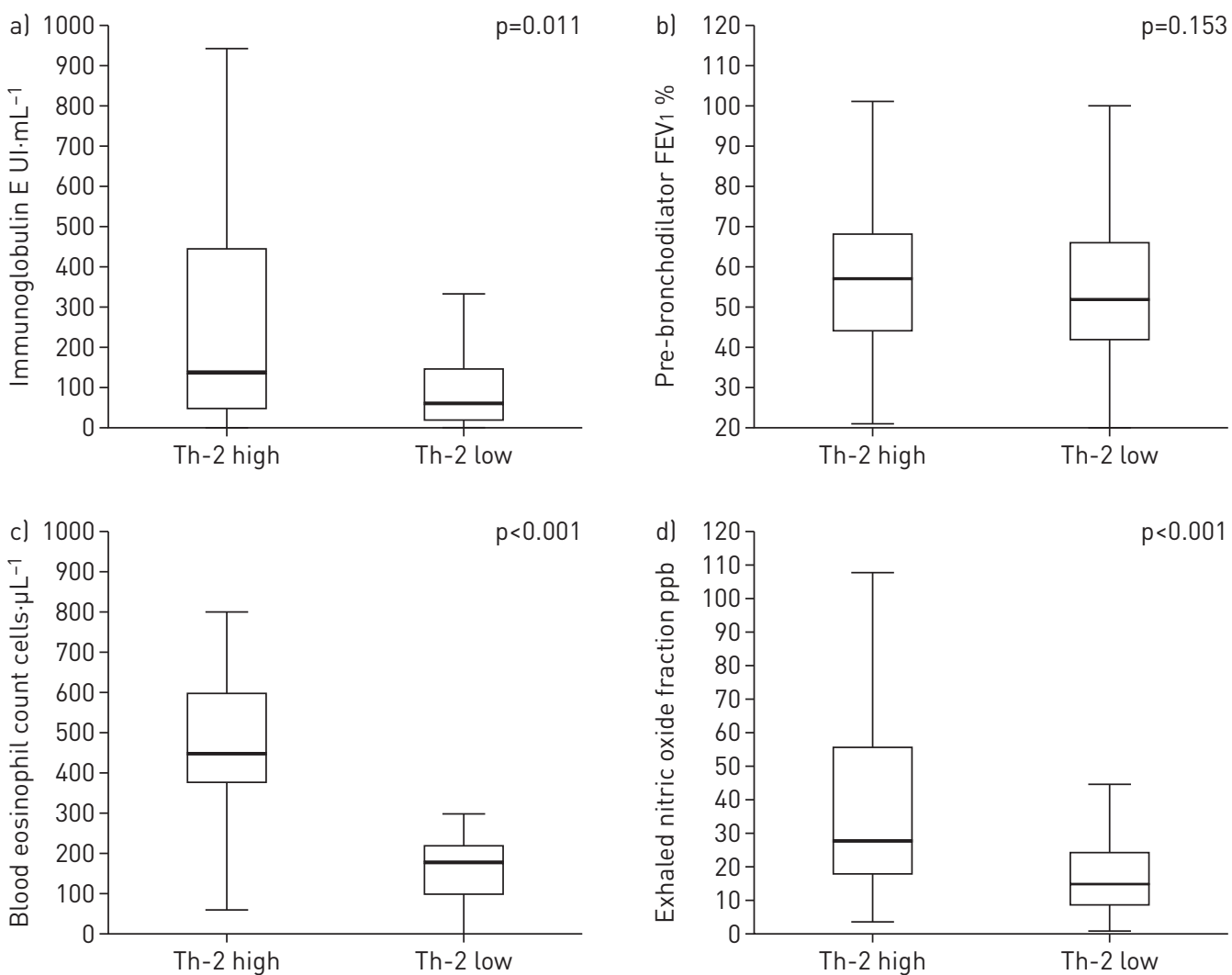

FIGURE 4 Differential characteristics according to the baseline inflammatory pattern. FEV1: forced expiratory volume in $1 \mathrm{~s}$.

proportion of patients with a Th-2-high inflammatory pattern $(49.3 \%)$ was almost identical to that observed in NSA. Therefore, the "historic classification" does not reflect the inflammatory heterogeneity that exists behind COAD.

Previous attempts to cluster patients with both asthma and chronic airflow obstruction and COPD identified patients with severe and markedly variable airflow obstruction with features of atopic asthma, chronic bronchitis and emphysema [19]. GHEBre et al. showed that factor and cluster analyses of the sputum cytokine profiles in patients with COAD revealed three biological clusters that are separated by the expression of Th-2 cytokines [20]. There is also evidence that an allergic phenotype is associated with increased respiratory symptoms and risk of COPD exacerbations [21]. From a clinical perspective, identifying this group of patients is relevant because it has been reported that patients with ACOS have more frequent exacerbations, are more likely to have a severe exacerbation requiring hospitalisation, use more respiratory medications, and have more respiratory symptoms [22, 23]. However, there is endless discussion on how ACOS should be defined, and other authors have found that the ACOS phenotype was not clinically different at baseline, other than in the specific criteria used to define it [10], as we have observed here.

We have shown that a classification of COAD according to the presence of Th-2 inflammatory markers appropriately differentiates two groups of patients with different clinical expressions that can be considered treatable traits to guide therapy, irrespective of whether they had diagnoses of COPD or asthma. This suggests that it is reasonable to abandon the current approach of treating patients according to their diagnostic category, and to find treatable traits that justify effective interventions. Given the move towards personalised medicine [24], we propose here that a marker of Th-2 inflammation should be used to differentiate a pooled population of patients that share chronic airflow obstruction, making a new category of "overlapped" patients irrelevant. Using Th-2 inflammation in patients with COAD to determine therapy has some clear clinical implications: 1) it would identify patients who should receive ICS on top of long-acting single or dual bronchodilator therapy, reducing the excessive use of ICS in patients with COPD and thus reducing the side effects related to these drugs, e.g. pneumonia, osteoporosis, cataracts (it is worth noting that the NSA group showed a higher prevalence of osteoporosis, probably due to the long-term exposure to corticosteroids); 2) it would help to identify patients more likely to respond to 
biologic therapy; 3) it would provide a new perspective on non-eosinophilic asthma with chronic airflow limitation; and 4) it would end the continued discussion on the origin of airway diseases (Dutch and British hypothesis).

This Th-2 classification of COAD relies mainly on the use of blood eosinophil count, which is being widely employed in different trials with biological therapy aimed to block the Th-2 cascade. Thus, our inclusion criterion of 200 cells $\mu \mathrm{L}^{-1}$ has been used to test the efficacy of benralizumab in eosinophilic COPD [25]. In keeping with this, NEgewo et al. found that patients are unlikely to have sputum eosinophilia if their blood eosinophil count is $<200$ cells $\mu \mathrm{L}^{-1}$ [12]. Moreover, SchleICH et al. found a cut-off of 162 cells $\mu \mathrm{L}^{-1}$ identified a sputum eosinophil count $\geqslant 3 \%$ in a COPD population of 155 patients, being 215 cells $\mu \mathrm{L}^{-1}$ in those treated with high-dose ICS [26]. In view of these findings, the selected cut-off point to identify COPD-e $\left(\geqslant 200\right.$ cells $\left.\mu \mathrm{L}^{-1}\right)$ can be considered reasonable, although we are aware that a higher cut-off point would have a higher positive predictive value. By contrast, WAGENER et al. [27] found that, in asthmatic patients, blood eosinophil counts had the highest accuracy in predicting sputum eosinophilia, with the best cut-off point of $\geqslant 270$ cells $\mu \mathrm{L}^{-1}$; this is why we decided to classify COAD as Th-2-high when the eosinophil count is $\geqslant 300$ cells $\mu \mathrm{L}^{-1}$.

Our work has several limitations that deserve comment. First, we used arbitrary cut-off points of blood eosinophil counts to recruit patients and to define their Th-2 profile, but we used the available published information that supports this view, as explained above. However, we were more stringent in the definition of Th-2-high, using a cut-off of 300 cells $\mu \mathrm{L}^{-1}$, which is widely accepted [7]. Also, a large number of patients were receiving ICS and some of them were being treated with oral corticosteroids or omalizumab, which could have masked differences between groups and modified the expression of Th- 2 markers. In addition, it is well known that active smoking can decrease FeNO in adults. Finally, the limit of 20 pack-years of smoking exposure in asthmatics could be misleading. However, by using this limit, we ensured that this phenotype overlapped the characteristics of smoking-related inflammation with those of baseline asthmatic inflammation.

\section{Conclusions}

We have shown that ACOS is an entity that might have different faces with different therapeutic approaches. We propose an easy-to-apply method to look at COAD using blood eosinophil counts that can separate two groups of patients with different clinical characteristics who require different therapeutic approaches. This proposal needs to be validated in further studies, including clinical trials, to demonstrate the usefulness of this approach.

\section{Acknowledgements}

The authors are grateful to all the patients who participated in the study. A number of investigators that contributed to the study logistics are listed in the supplemental material.

Authors' contributions: B.G. Cosío and L. Pérez de Llano designed the study, recruited patients, analysed the results and wrote the manuscript. A. Lopez Viña, A. Torrego, J.L. Lopez-Campos, J.B. Soriano, E. Martinez Moragon, J.L. Izquierdo,

I. Bobolea, J. Callejas, V. Plaza, M. Miravitlles and J.J. Soler-Catalunya recruited patients and reviewed the manuscript. The rest of the CHACOS study team recruited patients.

\section{References}

1 Reddel HK, Bateman ED, Becker A, et al. A summary of the new GINA strategy: a roadmap to asthma control. Eur Respir J 2015; 46: 622-639.

2 Vestbo J, Hurd SS, Agusti AG, et al. Global strategy for the diagnosis, management, and prevention of chronic obstructive pulmonary disease: GOLD executive summary. Am J Respir Crit Care Med 2013; 187: 347-365.

3 Agusti A, Bel E, Thomas M, et al. Treatable traits: toward precision medicine of chronic airway diseases. Eur Respir J 2016; 47: 410-419.

4 Singh D, Kolsum U, Brightling CE, et al. Eosinophilic inflammation in COPD: prevalence and clinical characteristics. Eur Respir J 2014; 44: 1697-1700.

5 Brightling CE, McKenna S, Hargadon B, et al. Sputum eosinophilia and the short term response to inhaled mometasone in chronic obstructive pulmonary disease. Thorax 2005; 60: 193-198.

6 Christenson SA, Steiling K, van den Berge M, et al. Asthma-COPD overlap. Clinical relevance of genomic signatures of type 2 inflammation in chronic obstructive pulmonary disease. Am J Respir Crit Care Med 2015; 191: 758-766.

7 Woodruff PG, Modrek B, Choy DF, et al. T-helper type 2-driven inflammation defines major subphenotypes of asthma. Am J Respir Crit Care Med 2009; 180: 388-395.

8 Global Strategy for Asthma Management and Prevention, Global Initiative for Asthma (GINA) 2015. www. ginasthma.org/ Updated 2016. Date last accessed: November 20, 2016.

9 Sin DD, Miravitlles M, Mannino DM, et al. What is asthma-COPD overlap syndrome? Towards a consensus definition from a round table discussion. Eur Respir J 2016; 48: 664-673.

10 Cosio BG, Soriano JB, López-Campos JL, et al. Defining the Asthma-COPD overlap syndrome in a COPD cohort. Chest 2016; 149: 45-52. 
11 Soler-Cataluna JJ, Cosio B, Izquierdo JL, et al. Consensus document on the overlap phenotype COPD-asthma in COPD. Arch Bronconeumol 2012; 48: 331-337.

12 Negewo NA, McDonald VM, Baines KJ, et al. Peripheral blood eosinophils: a surrogate marker for airway eosinophilia in stable COPD. Int J Chron Obstruct Pulmon Dis 2016; 11: 1495-1504.

13 Plaza V, Fernández-Rodríguez C, Melero C, et al. Validation of the 'Test of the Adherence to Inhalers' (TAI) for asthma and COPD patients. J Aerosol Med Pulm Drug Deliv 2016; 29: 142-152.

14 Miller MR, Hankinson J, Brusasco V, et al. Standardisation of spirometry. Eur Respir J 2005; 26: 319-338.

15 Macintyre N, Crapo RO, Viegi G, et al. Standardisation of the single-breath determination of carbon monoxide uptake in the lung. Eur Respir J 2005; 26: 720-735.

16 ATS/ERS recommendations for standardized procedures for the online and offline measurement of exhaled lower respiratory nitric oxide and nasal nitric oxide, 2005. Am J Respir Crit Care Med 2005; 171: 912-930.

17 Paggiaro PL, Chanez P, Holz O, et al. Sputum induction. Eur Respir J 2002; 20: Suppl. 37, 37: 3s-8s.

18 Green RH, Brightling CE, McKenna S, et al. Asthma exacerbations and sputum eosinophil counts: a randomised controlled trial. Lancet 2002; 360: 1715-1721.

19 Weatherall M, Travers J, Shirtcliffe PM, et al. Distinct clinical phenotypes of airways disease defined by cluster analysis. Eur Respir J 2009; 34: 812-818.

20 Ghebre MA, Bafadhel M, Desai D, et al. Biological clustering supports both "Dutch" and "British" hypotheses of asthma and chronic obstructive pulmonary disease. J Allergy Clin Immunol 2015; 135: 63-72.

21 Jamieson DB, Matsui EC, Belli A, et al. Effects of allergic phenotype on respiratory symptoms and exacerbations in patients with chronic obstructive pulmonary disease. Am J Respir Crit Care Med 2013; 188: 187-192.

22 Hardin M, Silverman EK, Barr RG, et al. The clinical features of the overlap between COPD and asthma. Respir Res 2011; 12: 127.

23 van Boven JF, Roman-Rodriguez M, Palmer JF, et al. Comorbidome, pattern and impact of asthma-COPD overlap syndrome (ACOS) in real-life. Chest 2016; 149: 1011-1020.

24 Agusti A. The path to personalised medicine in COPD. Thorax 2014; 69: 857-864.

25 Brightling CE, Bleecker ER, Panettieri RA Jr, et al. Benralizumab for chronic obstructive pulmonary disease and sputum eosinophilia: a randomised, double-blind, placebo-controlled, phase 2a study. Lancet Respir Med 2014; 2 : 891-901.

26 Schleich F, Corhay JL, Louis R. Blood eosinophil count to predict bronchial eosinophilic inflammation in COPD. Eur Respir J 2016; 47: 1562-1564.

27 Wagener AH, de Nijs SB, Lutter R, et al. External validation of blood eosinophils, $\mathrm{FE}(\mathrm{NO})$ and serum periostin as surrogates for sputum eosinophils in asthma. Thorax 2015; 70: 115-120. 